\title{
Correction to: The probabilistic seismic hazard assessment of Germany-version 2016, considering the range of epistemic uncertainties and aleatory variability
}

\section{Gottfried Grünthal $^{1}$ (D) Dietrich Stromeyer ${ }^{1} \cdot$ Christian Bosse $^{1} \cdot$ Fabrice Cotton $^{1,2}$. Dino Bindi ${ }^{1}$}

Published online: 1 June 2018

(C) Springer Science+Business Media B.V., part of Springer Nature 2018

\section{Correction to: Bull Earthquake Eng https://doi.org/10.1007/s10518-018-0315-y}

One paragraph of the manuscript of the paper has been inadvertently omitted in the very final stage of its compilation due to a technical mistake. Since this paragraph discusses the declustering of the used earthquake catalogue and is therefore necessary for the understanding of the seismicity data preprocessing, the authors decided to provide this paragraph in form of a correction. The respective paragraph belongs to chapter 2 of the paper, where it was placed originally, and should be inserted into the published paper before the second to the last paragraph. The omitted text reads as follows:

"The applied PSHA requires the identification of foreshocks and aftershocks, i.e., the declustering of the basic earthquake catalogue. After declustering, the remaining earthquakes for the analyses are statistically independent, i.e., they follow a Poisson process. The employed technique is the one after Grünthal (1985), which uses three magnitudedependent window parameters concerning time windows for foreshocks, aftershocks

The original article can be found online at https://doi.org/10.1007/s10518-018-0315-y.

Gottfried Grünthal

ggrue @gfz-potsdam.de

Dietrich Stromeyer

stro@gfz-potsdam.de

Christian Bosse

bosse@gfz-potsdam.de

Fabrice Cotton

fcotton@gfz-potsdam.de

Dino Bindi

bindi@gfz-potsdam.de

1 Helmholtz Centre Potsdam, GFZ German Research Centre for Geosciences, Potsdam, Germany

2 Institute for Earth and Environmental Sciences, University of Potsdam, Potsdam, Germany 
and a distance window. In Burkhard and Grünthal (2009), the method was extended for $M_{w}>$ 6.6. Special tests were performed in the frame of the project PEGASOS (Coppersmith et al. 2009) to select the optimal declustering approach with the outcome that the scheme of Grünthal (1985) with its magnitude extension is the most suitable one. It is optimized for Central European conditions. It fits also best with respect to recent sequences, e.g., in Switzerland (Deichmann, pers. comm. 2002). Consequently, it was not only applied in PEGASOS and our own analyses but also in, e.g., Giardini et al. (2004, p. 39), Hiemer et al. (2014), Woessner et al. (2015) or in Wiemer et al. (2016). The identified foreshocks and aftershocks, mostly small magnitude events often within earthquake swarms, represent about $48 \%$ of the total number of events but only $5 \%$ of the total seismic energy release."

The references therein are part of the paper, except:

Giardini D, Wiemer S, Fäh D, Deichmann N (2004) Seismic hazard assessment of Switzerland, 2004. Swiss Seismological Service, ETH Zurich. http://www.seismo.ethz.ch/static/stat_2010_website/stat-websi te-pre2010/www.earthquake.ethz.ch/research/Swiss_Hazard/Swiss_Hazard/downloads/Hazard_repor t_2004.pdf

Grünthal G (1985) The up-dated earthquake catalogue for the German Democratic Republic and adjacent areas - statistical data characteristics and conclusions for hazard assessment. 3rd International Symposium on the Analysis of Seismicity and Seismic Risk, Liblice/Czechoslovakia, 17-22 June 1985 (Proceedings Vol. I, 19-25)

Hiemer S, Woessner J, Basili R, Danciu L, Giardini D, Wiemer S (2014) A smoothed stochastic earthquake rate model considering seismicity and fault moment release for Europe. Geophysical Journal International 198(2): 1159-1172. https://doi.org/10.1093/gji/ggu186 